\title{
Capacidade deliberativa e de acompanhamento de políticas em Conselhos de Assistência Social
}

\author{
Deliberative capacity and policy monitoring in social assistance councils
}

\begin{abstract}
Márcia Batista Costa * Anselmo Sebastião Botelho **

\section{Resumo:}

O artigo resulta de uma pesquisa voltada para a análise da efetividade deliberativa dos Conselhos de Assistência Social em cidades do interior, tendo como parâmetro um estudo de caso no município de Abaeté, em Minas Gerais. O propósito foi avaliar a Política de Assistência Social adotada no município, além de buscar identificar as atribuições e o papel do Conselho no tocante às ações voltadas para a assistência social, bem como a sua relação com a administração pública municipal. Os resultados apontam fragilidades no processo participativo, limitando a atuação do Conselho na formulação e no controle das ações relativas à política municipal de assistência social.
\end{abstract}

Palavras-chave: Conselho de assistência social. Deliberação. Política de assistência social.

\begin{abstract}
:
The article is research's result that seek to analyze the effectiveness of deliberative Social Assistance Councils in towns. The parameter was the case study of Abaeté, in Minas Gerais, and the purpose was to evaluate the Social Assistance Policy adopted in the city, trying to identify the responsibilities and the role of the Council in regard to the actions directed for social assistance, as well as their relationship with the municipal public administration. The results point out failure in the participatory process, limiting the role of the Council in the formulation and control of actions related to municipal policy on social assistance.
\end{abstract}

Keywords: Social assistance council. Deliberation. Social assistance policy.

\section{Introdução}

Dentre as principais atribuições e competências dos Conselhos de Assistência Social, encontram-se a análise e a aprovação das políticas nos âmbitos das administrações estaduais do Distrito Federal e municipais, observando-se a Política Nacional de Assistência Social e as diretrizes das Conferências de Assistência Social. Dentre as funções dos Conselhos, podem-se destacar: organizar as Conferências de Assistência Social, aprovar suas normas de funcionamento, constituir a comissão organizadora e participar

\footnotetext{
* Universidade do Estado de Minas Gerais. Doutorado em Ciências Sociais pela UNICAMP. E-mail: academicomarcia@hotmail.com

** Universidade do Estado de Minas Gerais. Mestre em Desenvolvimento Regional pela UEMG. E-mail: abotelho@divinopolisuemg.com.br
} 
da elaboração do seu regimento interno; acompanhar, avaliar e fiscalizar a gestão dos recursos, os resultados e benefícios da implantação dos projetos sociais; e trabalhar pela implementação do Sistema Único de Assistência Social (SUAS) com a efetiva participação dos segmentos sociais representados nos Conselhos. Torna-se importante ressaltar que cabe aos Conselhos aprovar proposta orçamentária dos recursos destinados às ações de assistência social, além de definir os critérios de partilha desses recursos a partir dos parâmetros estabelecidos pela Lei Orgânica da Assistência Social (LOAS). Os Conselhos devem também divulgar e promover a defesa dos direitos socioassistenciais dos cidadãos, dentre outras atribuições e competências (CONSEAS-SP, 2014).

Considerando-se estas atribuições, verifica-se que os Conselhos de Assistência Social consistem em instâncias deliberativas no que tange desde a elaboração das políticas públicas de assistência social até a distribuição, o controle e a fiscalização dos recursos destinados à implantação dos projetos sociais nos estados, no Distrito Federal e nos municípios.

De acordo com Silva (2003), atualmente as políticas de assistência social no Brasil possuem grande relevância no combate à miséria e às desigualdades sociais. A partir dessas políticas, estabeleceu-se uma rede de proteção social cujos princípios fundamentais encontram-se insculpidos na Constituição Federal de 1988 - estes princípios visam proteger as pessoas que vivem em situações de vulnerabilidades sociais.

Entretanto, a efetivação destes princípios constitucionais é possível somente a partir da intermediação dos Conselhos de Assistência Social nos vários níveis governamentais. Estes Conselhos são resultados de lutas políticas por direitos sociais e foram concebidos para funcionar como peças fundamentais no mapeamento, na delimitação, na definição e no estabelecimento dos programas instituídos pelas políticas de assistência social. Os Conselhos são de extrema relevância para a implantação da Política de Assistência Social nos níveis federativos, instâncias nas quais a sociedade civil e o governo são responsáveis pela democratização dos benefícios sociais, a partir da gestão dos recursos destinados para tal fim (SILVA, 2003).

Os Conselhos de Assistência Social nos níveis Federal, Estadual e Municipal representam (ou deveriam representar) as instâncias deliberativas da Política de Assistência Social. Essas instâncias foram concebidas para promover e fortalecer a 
descentralização e, por isso, possuem composição paritária de representações do governo e da sociedade civil.

Os primeiros estudos desenvolvidos sobre os Conselhos como espaços públicos de concepção e de deliberação sobre políticas sociais se voltaram para a análise do desenho institucional paritário e para o funcionamento dessas esferas. Verificou-se, mais recentemente, no entanto, a necessidade de se avaliar qual a capacidade dos Conselhos de efetivamente interferirem nas decisões dos governos municipais em termos da definição e controle das políticas. O foco deste estudo de caso no município de Abaeté é a Política de Assistência Social, na perspectiva de se compreender a capacidade deliberativa do Conselho e sua relação com o órgão da administração municipal responsável pela política. Trata-se de pesquisa de caráter acadêmico, sustentada na metodologia qualitativa pela aplicação de entrevistas de tipo semiestruturadas no que se refere ao roteiro aplicado. Os entrevistados foram os membros do Conselho em diferentes gestões $^{1}$. É importante salientar, como parte do método aplicado, a realização de amplo estudo documental das atas do Conselho, bem como nos resultados das Conferências Municipais de Assistência Social, além da legislação sobre assistência social vigente no país.

Tomando como referência todo o percurso da política de assistência social no Brasil, a importância dos Conselhos nas esferas de governo e a condição determinante desses espaços públicos nas instâncias subnacionais, apresentam-se como relevante os resultados de estudos sobre a atual situação dessas esferas como espaços compartilhados de deliberação sobre políticas públicas. Este artigo é resultado de pesquisa desenvolvida com o objetivo de sistematizar conhecimentos acerca da relevância dos Conselhos de Assistência Social no processo de formulação, implantação e gestão das políticas e, consequentemente, de recursos destinados aos programas de assistência social na esfera municipal. O foco foi a análise da efetividade deliberativa dessas instâncias, a partir do estudo de caso do Conselho Municipal de Assistência Social (CMAS) de Abaeté, em Minas Gerais.

\footnotetext{
1 A pesquisa foi realizada no âmbito do Programa de Mestrado em Desenvolvimento Regional da Universidade do Estado de Minas Gerais - UEMG entre os meses de junho de 2013 e julho de 2014. Todos os conselheiros entrevistados foram informados sobre a proposta do estudo e assinaram o Termo de Consentimento Livre e Esclarecido.
} 
O município de Abaeté encontra-se localizado na região Centro-Oeste do Estado de Minas Gerais. A cidade se sustenta, basicamente, em uma economia rural, embora tenha apresentado taxa de urbanização ampliada de 2000, com 85,06\%, para 86,84\% em 2010, conforme o Censo. As fragilidades sociais podem ser constatadas nos dados do Censo Demográfico de 2010 que estimam a taxa de extrema pobreza da população em 7,62\% (IBGE, 2014), fato que demanda acompanhamento cuidadoso dos órgãos de assistência social.

Por meio da pesquisa, buscou-se analisar o nível de efetividade deliberativa do CMAS no que se refere às definições sobre a Política de Assistência Social do município. A intenção foi identificar o papel do Conselho na definição e acompanhamento das políticas de assistência social e as peculiaridades da relação entre o CMAS e a administração municipal.

Acredita-se que a realidade investigada na cidade de Abaeté representa um recorte da situação dos Conselhos Municipais de Políticas Públicas em funcionamento nos municípios do interior. Trata-se de recorte importante, tanto pela carência de estudos fora dos grandes centros urbanos como pelos dados recentes do caso analisado, demonstrando como as cidades de médio e pequeno porte têm apresentado problemas sociais tão sérios quanto os das grandes cidades. Destacou-se a Política de Assistência Social, consolidada a partir do marco legal representado pela LOAS, aprovada em 1999.

\section{A política de assistência social e o papel dos Conselhos}

O processo histórico da política de Assistência Social no Brasil traz marcas de ligação com a pobreza e com a insuficiência de clareza em relação às suas atribuições específicas, fato que não foi suficientemente alterado com o seu reconhecimento legal como política social (REIS; PESTANO, 2006, p. 3).

De acordo com Netto (2000), a assistência social tem origem em uma estrutura legal e legítima com o objetivo de disponibilizar segurança social aos cidadãos que não se encontram protegidos pelo sistema de contribuições. Nesse sentido, a assistência social busca resgatar esses cidadãos que não têm capacidade de contribuir e incluí-los na malha de proteção contra as adversidades causadas por enfermidades, velhice, abandono, desemprego, desagregação familiar, exclusão social, dentre outras mazelas. 
Atualmente, a definição das políticas públicas de assistência social considera três dimensões para a sua formulação. De acordo com Brasil (2005, p. 15), essas dimensões são:

[...] as pessoas, as suas circunstâncias e dentre elas seu núcleo de apoio primeiro, isto é, a família. A proteção social exige a capacidade de maior aproximação possível do cotidiano da vida das pessoas, pois é nele que riscos e vulnerabilidades se constituem.

O estabelecimento das políticas públicas de assistência social é necessário em função da expressiva desigualdade que se observa no Brasil. O país figura entre aqueles cujas desigualdades são mais acentuadas. Assim, quando as pessoas não têm oportunidades iguais de acesso aos bens necessários à sua sobrevivência, o Estado e a própria sociedade civil, em suas múltiplas formas de organização, devem entrar em cena para proporcionarem, de forma artificial, melhores condições de vida para a sua população (COMERLATTO et al., 2007).

Os Conselhos foram os instrumentos por excelência utilizados para colocar em prática as políticas sociais, nas quais por um lado encontra-se o poder público e, por outro, a sociedade civil organizada, acompanhando e fiscalizando esse processo,

[...] a participação social na gestão das políticas públicas vem se ampliando desde a formalização dos conselhos gestores de políticas públicas, a instituição dos fundos orçamentários e a elaboração dos planos na atenção local. Essas políticas são reconhecidas como instrumentos necessários que fortalecem o processo de descentralização para assegurar os interesses da grande maioria da população. Dessa forma, entram em cena novos atores na gestão dos serviços públicos com atribuições partilhadas, resignificando as relações de poder em prol de decisões e práticas intersetoriais que assegurem o acesso e a efetivação de direitos sociais (COMERLATTO et al., 2007, p. 266).

Essa ressignificação aludida pelos autores remete à busca do aperfeiçoamento do processo de elaboração, implementação e fiscalização das políticas públicas em busca de sua adequação ao pleno atendimento das necessidades de grupos sociais em vulnerabilidade social.

Existem vários aspectos que influenciam decisivamente na criação das políticas públicas de assistência social, sendo um destes o demográfico, uma vez que a dinâmica populacional de um determinado território define aspectos como a distribuição de renda, a valorização do solo, taxas de urbanização, saneamento e infraestrutura. Na maioria das 
cidades consideradas de grande porte, pode-se observar a precarização das condições de vida das populações mais carentes e um acentuado acirramento das desigualdades socioeconômicas da população, assim como a elevação dos níveis de pobreza (BRASIL, 2005).

Outro aspecto que possui relevante influência no estabelecimento de políticas públicas é a desaceleração das taxas de natalidade da população brasileira, fenômeno que se iniciou a partir da década de 1970 e que vem apresentando acentuado declínio década após década. Esse fenômeno causa uma alteração significativa na pirâmide etária brasileira, uma vez que o seu topo tende a alargar-se e, assim, elevar a expectativa de vida da população que está envelhecendo rapidamente (BRASIL, 2005).

Fica evidente que os custos sociais aumentam, significativamente, devido ao envelhecimento da população, pois a rede de proteção a essas pessoas é mais complexa, exigindo recursos e políticas específicas.

Com relação ao controle social exercido sobre a formulação das políticas de assistência social e sobre as ações estatais, Pedrini e Pinheiro (2005, p. 34) observam que,

[..] no âmbito da assistência social, a participação popular foi efetivada na Lei Orgânica da Assistência Social (artigo 50-II), ao lado de duas outras, a descentralização político administrativa para estados e municípios, o comando único em cada esfera de governo (artigo 50-I) e a primazia da responsabilidade do Estado na condução da política de assistência social em cada esfera de governo (artigo 50-III).

Neste sentido, percebe-se que o controle social passa a ser uma questão regulamentada na Constituição e na LOAS, levando à atuação direta dos representantes da sociedade civil. Esse controle busca estabelecer os debates e as reflexões necessários ao aperfeiçoamento das políticas e à efetiva atuação dos Conselhos nesse processo.

No tocante às políticas públicas, os Conselhos deveriam assumir, portanto, papel primordial como espaços públicos de concepção e acompanhamento das ações de governo, em interlocução direta com os órgãos responsáveis pela concepção e desenvolvimento das políticas de assistência social. Entende-se que os marcos legais foram instituídos para garantir a administração democrática e descentralizada das políticas setoriais, com a participação ativa da sociedade civil. O que se percebe, empiricamente, é uma tendência de fragilização dos Conselhos. Inicialmente com práticas 
de interferir nas políticas e, mais recentemente, com práticas mais susceptíveis à perda de autonomia, de capacidade de efetivar deliberações e de exercer papel de controle social.

\section{Participação, articulação, deliberação e as relações entre o Conselho e o Governo}

Segundo Correia (2002), os Conselhos são responsáveis pela formulação e pela fiscalização/controle do processo de aplicação da Política de Assistência Social, uma vez que possuem o poder de deliberação sobre esse processo, o que influencia decisivamente no processo de construção do Plano Municipal de Assistência Social, bem como em sua operacionalização.

Barros e Carvalho (2003, p. 5) chamam a atenção para o processo deliberativo, questionando:

\footnotetext{
A incapacidade da sociedade brasileira em reduzir o seu alto grau de desigualdade e, portanto, a sua não utilização desse importantíssimo instrumento para o combate à pobreza e à extrema pobreza, pode resultar de dois fatores: a) ausência de uma política social ou b) baixa efetividade da política existente.
}

Para os autores, o Brasil possui um montante considerável de verbas destinadas às políticas públicas de assistência social. Entretanto, a questão não se obstrui apenas nos orçamentos, mas, sim, na efetividade das políticas, pois as desigualdades persistem no país.

Avritzer (2011) destaca a efetividade das decisões, uma vez que diversos pesquisadores passaram a tentar decifrá-la por meio de duas frentes de estudo.

A primeira questão levantada foi a crescente associação entre participação e políticas públicas que, no caso brasileiro, tem características específicas, seguindo critérios espelhados nas políticas deliberativas adotadas, principalmente, nas áreas da assistência social, saúde e políticas urbanas. A segunda questão foi descrita como uma "preocupação de caráter mais teórico em relação ao tema da deliberação" (DRYZEK, 2000; FUNG; WRIGHT, 2003, apud AVRITZER, 2011). O autor definiu deliberação como "[...] a capacidade das instituições influenciarem, controlarem ou decidirem sobre determinada política [...]" (CUNHA, 2010, apud AVRITZER, 2011, p. 17). 
No Brasil, existem milhares de instituições utilizando a participação social, localizadas em todos os níveis de governo (União, estados, municípios e Distrito Federal), atuando nas diversas áreas das políticas públicas (saúde, segurança, assistência social, entre outras). Assim, ao se discutir a efetividade, torna-se necessária a construção de alguma forma avaliativa das ações e das características dessas instituições, além da necessidade de enfatizar os resultados alcançados por elas (AVRITZER, 2011). Considerando a relação entre Conselho e governo municipal de Abaeté, observam-se falhas no processo participativo previsto na ideia de descentralização e participação ativa da sociedade civil, ou seja, não existe no município analisado uma participação efetiva de membros e representantes da sociedade civil (representantes de bairros, presidentes de associações comunitárias etc.), para apresentarem e enriquecerem as propostas de elaboração da Política Pública de Assistência Social e alocação dos recursos. Desta forma, pode ficar comprometida a capacidade do Conselho em deliberar com autonomia. Com efeito, ele torna-se limitado para interferir, efetivamente, na formulação e no controle das ações relativas à Política Municipal de Assistência Social.

\section{Interferência do poder executivo: uma prática}

Na perspectiva de Santos (2002), os Conselhos são os instrumentos responsáveis por articular o processo de formulação das diretrizes, estabelecendo as prioridades, os programas sociais e as formas de acompanhamento e controle da gestão das políticas públicas. Para tanto, faz-se necessário que o poder público aja com a máxima transparência possível no que tange ao fornecimento de informações dos indicadores sociais indispensáveis ao planejamento das ações e sua posterior avaliação.

Foi possível constatar, pelos dados levantados e pelas observações, que existe um controle do governo sobre o funcionamento do Conselho. A Secretaria de Assistência Social tem assumido o papel de definir as pautas e a condução das reuniões para fins de aprovação de recursos. Desde a sua criação, o Conselho teve como presidentes, majoritariamente, representações do poder executivo. Outros dados levantados mostram a predominância do governo nos processos decisórios. 
Em reunião acompanhada2, se apresentaram conselheiros representantes do governo, como a secretária de Assistência Social, representante da Secretaria de Saúde, representante do setor de Finanças da Prefeitura, representantes do Centro de Referência Especializada em Assistência Social (CREAS) e do Centro de Referência em Assistência Social (CRAS) e de apenas duas entidades da sociedade civil, a Associação de Pais e Amigos dos Excepcionais (APAE) e a Sociedade de São Vicente de Paulo (SSVP).

Esta disparidade aumenta a partir do momento em que, na reunião supracitada, compareceram, além dos titulares das entidades governamentais, seus suplentes, que, mesmo sem direito a voto, opinaram sobre os assuntos tratados. É importante uma maior diversidade relativa à participação da sociedade civil no CMAS a fim de que a Política de Assistência Social no município não fique direcionada apenas às necessidades do governo e/ou a essas entidades exclusivamente.

Os Conselhos podem assumir, conforme o contexto e os interesses locais, uma série de características diferentes. Podem apresentar, por exemplo, um caráter centralizador quando o poder público municipal apresenta dificuldades em reconhecer que os Conselhos são espaços privilegiados para a relação entre o Estado e a sociedade. Também podem não cumprir seu papel frente aos interesses sociais no momento em que os seus membros representantes da sociedade civil não demonstram o devido interesse em participar das decisões do Conselho, ou mesmo quando os processos, ao serem coordenados por representações de governo, inibem a participação efetiva e consistente da sociedade civil.

A realidade do CMAS de Abaeté mostra a falta de interesse e de participação dos conselheiros representantes da sociedade civil. Mostra, além disso, a falta de interesse em relação às peculiaridades do processo de elaboração das políticas e das formas de decisão que, basicamente, seguem orientações do poder executivo municipal.

Conforme análise de atas, apenas duas entidades da sociedade civil, atualmente, se apresentam frequentes às reuniões do Conselho, deixando as decisões nas mãos dos órgãos governamentais. Outro ponto verificado nas atas e observado é que essas reuniões estão se tornando uma simples ferramenta de prestação de contas,

\footnotetext{
${ }^{2}$ Observação de reunião do CMAS realizada em 19 de março de 2014.
} 
desvirtuando o espaço de debate e deliberação representado pelo Conselho, caracterizado por frágil participação.

O CMAS de Abaeté teve sua primeira reunião registrada no ano de 1997. Naquela ocasião, a composição do Conselho ocorreu de forma paritária, apresentando uma grande variedade de representantes da sociedade civil. Havia representantes da entidade de proteção à infância e à adolescência, da APAE, da Vila Vicentina e do Instituto Paroquial de Assistência Social. É importante salientar que completavam o Conselho: representantes de classes, assistente social e psicóloga e representante das associações comunitárias, da cooperativa dos produtores rurais e dos trabalhadores rurais. ${ }^{3}$

Uma análise detalhada das últimas atas mostra, porém, que o CMAS de Abaeté perde sua diversidade interna, chegando ao ano de 2014 apenas com representantes da APAE e da Vila Vicentina ${ }^{4}$ e de representantes do governo.

Outro ponto preocupante nos rumos que o Conselho vem tomando refere-se à presença de convidados pertencentes aos órgãos do poder executivo nas reuniões, principalmente gestores e funcionários do CRAS e do CREAS, tendo em vista que, ao atuarem no órgão municipal responsável pela Política de Assistência Social, podem, pelo número, definir procedimentos em favor do poder público e influenciar as decisões dos demais conselheiros. ${ }^{5}$

Um representante da sociedade civil ${ }^{6}$ considerou que, de forma geral, as questões colocadas em pauta são deliberadas sem debates ou questionamentos por parte dos membros do Conselho. Este fato desestimula a participação e tolhe a iniciativa dos conselheiros.

Outro conselheiro ${ }^{7}$, também da sociedade civil, considerou que os representantes do governo são mais participativos do que aqueles da sociedade civil. Neste caso, é necessário que os representantes da sociedade civil busquem novos conhecimentos das normas e resoluções, inteirando-se do que está acontecendo nos níveis estadual e nacional para que possam aplicá-las no município e ter mais efetividade no que se refere à sua representação e ao seu poder de decisão.

\footnotetext{
${ }^{3}$ Ata da reunião do CMAS de Abaeté realizada em 16 de janeiro de 1997.

${ }^{4}$ Atas das reuniões do CMAS de Abaeté realizadas nos meses de janeiro a maio de 2014.

${ }^{5}$ Atas da reuniões do CMAS de Abaeté realizadas nos meses de janeiro a maio de 2014.

${ }^{6}$ Conselheiro representante da sociedade civil - Entrevistado no 1 (entrevista realizada em 12/5/2014).

${ }^{7}$ Conselheiro representante da sociedade civil - Entrevistado no 2 (entrevista realizada em 25/2/2014).
} 


\section{Aspectos da organização da política de assistência: como acontece nos municípios}

Em relação às definições sobre as políticas de assistência social, torna-se importante destacar que falta investimento da administração local para a realização de diagnóstico sobre a real situação do público destinatário das políticas. Levantamentos sistemáticos favoreceriam o planejamento das ações estabelecidas com metas e objetivos claros. Proceder a tal análise permitiria identificar as particularidades da população e as áreas da cidade onde vivem as pessoas que necessitam das políticas sociais, podendo ser avaliadas a real situação de risco e a vulnerabilidade dos cidadãos.

Nas administrações municipais, há uma tendência de falta de diagnósticos que indiquem as políticas sociais. Se os Conselhos cumprissem com mais autonomia o papel de deliberar e acompanhar e se os governos acatassem, de maneira mais responsável, as deliberações, as ações de governo poderiam se tornar mais eficazes e verdadeiramente participativas. É por essa razão que estudos sobre a efetividade deliberativa dos Conselhos setoriais de políticas públicas, no caso em questão o estudo sobre o Conselho de Assistência Social de Abaeté, ajudam a compreender como essas esferas paritárias cumprem seu papel de deliberar sobre políticas e como os governos acatam as deliberações e, de fato, atuam direcionando ações priorizadas pelo Conselho.

Um aspecto tem sido muito discutido em estudos realizados acerca da efetividade deliberativa no contexto político das administrações. Esse aspecto está mais relacionado ao problema da qualidade do processo deliberativo e não tanto aos resultados do processo de agregação política de opiniões construídas de forma descentralizada. Ou seja, é mais relevante considerar a qualidade do processo e das discussões do que considerar, apenas, a metodologia descentralizadora na formulação das políticas públicas (COHEN, 1997 apud AVRITZER, 2011).

Um representante do governo ${ }^{8}$ no Conselho considerou que a efetividade das políticas públicas é prejudicada pelo próprio poder executivo de modo geral. O governo tem uma visão distorcida do Conselho, enxergando-o como um órgão questionador e de oposição quando, na verdade, o Conselho poderia ser um aliado e um parceiro.

\footnotetext{
${ }^{8}$ Conselheiro representante do governo - Entrevistado no 4 (entrevista realizada em 25/2/2014).
} 
Outro aspecto que prejudica a atuação mais consistente do Conselho, segundo outro entrevistado ${ }^{9}$, é a falta de informação tanto do governo quanto dos próprios conselheiros. O entrevistado ressaltou que, para ser conselheiro, é preciso estudar a política e se capacitar, buscando conhecimentos sobre as leis e normas relacionadas às políticas públicas de assistência social. Percebe-se que a questão da efetividade passa também, necessariamente, pela qualidade da atuação dos conselheiros.

Neste sentido, Avritzer (2011) observa-se que um dos maiores problemas da efetividade participativa está relacionado ao contexto político, o qual pode ser representado pelos ambientes econômico, político e social. Estes, por sua vez, são responsáveis pela efetividade das políticas públicas. Assim, o componente político possui maior poder de decisão, influenciando, decisivamente, nas formas de deliberação.

As análises das entrevistas demonstram a visão dos conselheiros representantes da sociedade civil e do governo sobre quais foram as deliberações mais importantes ocorridas no CMAS e acatadas pelo poder público. Ao buscar compreender a efetividade deliberativa do Conselho, foram incluídas perguntas no roteiro sobre o foco das políticas e sobre o comportamento do governo municipal. Os entrevistados foram consultados sobre as ações mais relevantes desenvolvidas e sobre a posição do poder executivo ao acatar as deliberações do Conselho. As respostas apontam aspectos que favorecem algumas interpretações, embora o tema mereça aprofundamento.

Em entrevista, um representante da sociedade civil ${ }^{10}$ observou que a ação/proposta mais relevante da Política de Assistência Social desenvolvida pelo CMAS de Abaeté foi a implantação do serviço de convivência. Segundo o entrevistado,

[...] este serviço era o antigo PETI, que agora foi unificado dentro da assistência, se tornando, assim, o serviço de convivência desenvolvido pelo CRAS do município, onde aborda os adolescentes. Trata-se de um trabalho preventivo e direcionado aos adolescentes. [Disse ainda que] há grande influência do poder executivo e da secretaria sobre as deliberações e certo nivel de pressão do poder executivo.

O representante conselheiro ${ }^{11}$ ainda citou a regulamentação do processo de distribuição de cestas básicas no município como fato preponderante discutido no

\footnotetext{
${ }^{9}$ Conselheiro representante do governo - Entrevistado no 5 (entrevista realizada em 26/2/2014).

${ }^{10}$ Conselheiro representante da sociedade civil - Entrevistado no 1 (entrevista realizada em 12/5/2014).

${ }^{11}$ Conselheiro representante da sociedade civil-Entrevistado no 1 (entrevista realizada em 12/5/2014).
} 
Conselho. Para o conselheiro em questão, esse fato levará organização e mais justiça às famílias que recebem este benefício, visto que evitará que algumas famílias recebam mais de uma cesta básica e outra, que também necessite, fique sem recebê-la.

De forma incisiva, o membro do Conselho ${ }^{12}$ observou ainda que, quando são apresentadas questões ou mesmo tomadas decisões por parte do poder executivo, geralmente tais decisões não sofrem o crivo nem são debatidas pelo Conselho. Por outro lado, o poder executivo não acata as decisões tomadas pelo Conselho quando essas não Ihes são favoráveis ou não estejam de acordo com os interesses do governo.

Continuando a entrevista, o conselheiro representante da sociedade civil mostrouse preocupado ao falar sobre decisões tomadas pelo Conselho e que não foram acatadas pelo governo: "Acredito que, principalmente, as questões que são votadas nas conferências, que são tópicos dentro de cada eixo, no qual tem que ser cobrado do governo e não foram realizadas".

Para outro entrevistado ${ }^{13}$, a ação deliberativa mais relevante do Conselho, relativa à Política de Assistência Social, foi "a adequação das entidades à resolução que trata da nova forma de inscrição e do papel de cada uma das entidades civis como elemento da rede socioassistencial". Sobre a questão da qualidade deliberativa, o conselheiro afirmou que,

[...] os conselheiros ainda não foram capacitados, os representantes da sociedade civil estão em minoria e a representatividade do governo é mais bem preparada. O grau de envolvimento do poder executivo é maior do que o da sociedade civil e, por isso, tenta impor suas vontades e questões para que o Conselho as aprove. ${ }^{14}$

O conselheiro ${ }^{15}$ ponderou também que o poder executivo acata as decisões do Conselho no momento em que se consegue tomar uma decisão unânime e criar uma resolução apoiada por todos os conselheiros. Entretanto, ele critica a inércia do governo ao não acatar algumas decisões do Conselho, exemplificando a casa do Conselho, sendo que "já se passou por duas conferências esse pedido e ainda não foi concretizado, o qual é de suma importância, até mesmo para avaliar as ações em grupo".

\footnotetext{
${ }^{12}$ Conselheiro representante da sociedade civil-Entrevistado no 1 (entrevista realizada em 12/5/2014).

${ }^{13}$ Conselheiro representante da sociedade civil-Entrevistado no 2 (entrevista realizada em 25/2/2014).

${ }^{14}$ Conselheiro representante da sociedade civil-Entrevistado no 2 (entrevista realizada em 25/2/2014).

${ }^{15}$ Conselheiro representante da sociedade civil-Entrevistado no 2 (entrevista realizada em 25/2/2014).
} 
Outro representante da sociedade civil entrevistado ${ }^{16}$, ao falar da questão da deliberação no Conselho, ressaltou que as ações/propostas mais relevantes da Política de Assistência Social do Conselho, além da consolidação da distribuição de cestas básicas, foram as ações implementadas pelo serviço de convivência. Também afirmou que está havendo uma fiscalização mais intensa para o controle efetivo das políticas, tanto por parte das entidades sobre as ações do município quanto do município sobre as ações das entidades.

Por outro lado, o conselheiro ${ }^{17}$ destacou que "o Conselho tem autonomia para conduzir as suas pautas de discussões, mas, em função da maior representatividade do governo no Conselho, as decisões tendem a favorecer o poder executivo". Já sobre os representantes do Conselho, ressaltou que os representantes da sociedade civil são mais atuantes do que os do governo. Por fim, criticou o fato de que as questões da pauta nem sempre são debatidas.

Todavia, o entrevistado ${ }^{18}$ sugeriu que, para haver maior efetividade das ações/políticas do Conselho, é necessário que os conselheiros representantes do poder executivo elaborem projetos mais interessantes para colocarem em pauta e serem discutidos nas reuniões. Complementando, o entrevistado não se recordou se houve deliberações aprovadas no Conselho que não fossem acatadas pelo poder público.

Para outro conselheiro ${ }^{19}$ entrevistado, a deliberação mais importante do CMAS foi a organização da rede de proteção da assistência social:

[...] das ações mais relevantes do Conselho foi a organização das redes de proteção e assistência social, pois foi a partir daí que foi possível estruturar as comissões de fiscalização e acompanhamento das entidades, monitoramento do Bolsa Família, para verificar se essas políticas estão funcionando corretamente $e$ se estão sendo efetivas e bem direcionadas.

Em relação às políticas de assistência social e suas normas, o conselheiro disse que ocorreram avanços relacionados às recentes regulamentações. Quanto ao acompanhamento das decisões relativas às propostas apresentadas pelo governo, informou que esse acompanhamento ocorre de maneira não formalizada e não

\footnotetext{
${ }^{16}$ Conselheiro representante da sociedade civil - Entrevistado no 3 (entrevista realizada em 5/3/2014).

${ }^{17}$ Conselheiro representante da sociedade civil - Entrevistado no 3 (entrevista realizada em 5/3/2014).

${ }^{18}$ Conselheiro representante da sociedade civil - Entrevistado no 3 (entrevista realizada em 5/3/2014).

${ }^{19}$ Conselheiro representante do governo - Entrevistado no 4 (entrevista realizada em 25/2/2014).
} 
sistematizada. Disse, ainda, que o poder executivo acata as decisões do Conselho, mas que o processo de tomada de decisões não é acompanhado, avaliado ou cobrado pelos membros do Conselho.

O entrevistado ${ }^{20}$ destacou, ainda, uma das deliberações do Conselho que não foi acatada pelo governo municipal, falando sobre a instituição do auxílio-natalidade destinado às pessoas carentes. Esse benefício é previsto na LOAS e foi aprovado pelo CMAS de Abaeté, mas o poder executivo do município negou a sua implantação. Ao ser questionado acerca do que atrapalha a efetividade das políticas definidas pelo Conselho, o conselheiro respondeu que "é o próprio executivo de modo geral. O governo tem uma visão distorcida do Conselho, enxergando-o como um órgão questionador e de oposição quando, na verdade, é um aliado e um parceiro".

Para que haja maior efetividade das ações e políticas do Conselho, o entrevistado ${ }^{21}$ respondeu que:

[...] os Conselheiros não podem perder o foco dos problemas sociais e devem ter ciência da importância do trabalho do Conselho para a coletividade, pois, quanto maiores e melhores forem os resultados e benefícios proporcionados aos cidadãos, tanto maior será o reconhecimento de que o Conselho é um instrumento efetivo de socialização e amparo aos mais necessitados. Também cobrar mais maturidade, interesse e participação dos conselheiros e reconhecer o poder executivo como um parceiro e não um adversário.

Para outro conselheiro 22 , as deliberações mais importantes foram "o controle de gastos das receitas das entidades, os planos de atividades e as formas de trabalho e atuação do próprio Conselho". O membro do Conselho ${ }^{23}$ acredita que:

[...] a representação do Conselho é paritária, o Conselho possui autonomia para definir suas pautas, o grau de envolvimento do governo é equilibrado e o poder executivo depende das deliberações do Conselho no que se refere à parte financeira dos programas sociais.

O entrevistado complementou sua fala comentando que as questões deliberadas no CMAS são sempre debatidas e que, por vezes, são formadas comissões para análise e apresentação das propostas que, posteriormente, passam pelo crivo dos conselheiros. Ao ser questionado se o governo acata as decisões do Conselho, disse que "depende da

\footnotetext{
${ }^{20}$ Conselheiro representante do governo - Entrevistado no 4 (entrevista realizada em 25/2/2014).

${ }^{21}$ Conselheiro representante do governo - Entrevistado no 4 (entrevista realizada em 25/2/2014).

${ }^{22}$ Conselheiro representante do governo - Entrevistado no 5 (entrevista realizada em 26/2/2014).

${ }^{23}$ Conselheiro representante do governo - Entrevistado no 5 (entrevista realizada em 26/2/2014).
} 
disponibilidade de recursos do município. Dessa forma, nem sempre é possível executar tudo aquilo que foi decidido pelo Conselho". Todavia, afirmou que as decisões mais importantes do Conselho foram acatadas pelo governo municipal e, ao contrário dos outros conselheiros, afirmou que até o momento nenhuma deliberação deixou de ser acatada pelo Governo.

O próximo conselheiro ${ }^{24}$ entrevistado é representante do governo. Para ele, as deliberações mais importantes foram a mudança da atenção primária para básica nos conceitos de enquadramento da assistência social no município e as deliberações feitas pelo Conselho sobre os critérios de distribuição dos benefícios eventuais de "cesta básica" para a população.

Ainda sobre as ações deliberativas, o entrevistado ${ }^{25}$ afirmou que o Conselho tem autonomia para definir e conduzir suas pautas e que não há grau algum de envolvimento do Conselho com o poder executivo. Entretanto, disse que algumas questões apresentadas são debatidas e outras não. Além disso, deixou escapar que algumas questões são apenas apresentadas pelos representantes do governo, não tendo espaço para discussões. Por outro lado, o conselheiro informou que as decisões do Conselho são sempre acatadas e implantadas pelo governo municipal.

O sétimo conselheiro entrevistado representa o governo no CMAS. Para ele, as ações mais relevantes relativas à Política Pública de Assistência Social, desenvolvidas pelo Conselho, foram a confirmação da implantação do CRAS e CREAS no município, bem como o suporte dado às instituições como a APAE, a Vila Vicentina e a Instituição Paroquial de Assistência Social (IPAS). ${ }^{26}$ O conselheiro destaca que "sempre haverá autonomia do Conselho para definir e conduzir as pautas, desde que o presidente do Conselho seja atuante. $\mathrm{O}$ envolvimento do poder executivo no Conselho é apenas para dar suporte às suas decisões".

Contrariando sua fala, o conselheiro afirmou que "nas reuniões, as questões, geralmente, não são debatidas, mas, somente, apresentadas para deliberação". ${ }^{27}$

\footnotetext{
${ }^{24}$ Conselheiro representante do governo - Entrevistado no 6 (entrevista realizada em 24/2/2014).

${ }^{25}$ Conselheiro representante do governo - Entrevistado no 6 (entrevista realizada em 24/2/2014).

${ }^{26}$ Conselheiro representante do governo - Entrevistado no 7 (entrevista realizada em 26/2/2014).

${ }^{27}$ Conselheiro representante do governo - Entrevistado no 7 (entrevista realizada em 26/2/2014).
} 
As atas também remetem às análises sobre as decisões do Conselho. Pode-se observar que muitos assuntos importantes são apenas apresentados, sem discussão prévia, como no caso da criação do CRAS em 2007. Na fala do presidente do Conselho naquele momento, "a criação do CRAS, que foi criado pra dar maior assistência às famílias carentes de nossa comunidade, e esta foi uma das deliberações da VI Conferência Municipal de Assistência Social". ${ }^{28}$

Como os presentes já estavam cientes das normas, colocou-se em votação para aprovação do pleito de habilitação do CRAS "[...] no qual foi aprovado por unanimidade".

Outro assunto apenas apresentado ao Conselho foi a criação do CREAS. Segundo a fala do presidente do Conselho naquela ocasião, "nosso município foi contemplado. Iremos iniciar até dezembro de 2010. O projeto (de implantação do CREAS) deve ser iniciado no bairro São Pedro, onde a prefeitura tem um imóvel”. ${ }^{29}$

Dentre os projetos discutidos no CMAS e retratados nas entrevistas, pode-se destacar o que regulamenta o processo de distribuição de cestas básicas no município. Esse projeto foi apresentado pela Secretaria de Assistência Social no dia 5 de fevereiro de 2014 e definia critérios para a concessão do benefício. Conforme análise da ata, o projeto "foi aprovado por todos". 30

Após a aprovação desse projeto, a Secretaria de Assistência Social tratou de publicar a Resolução 001/2014, apresentada em reunião extraordinária, informando a todos os "critérios para distribuição das cestas básicas para todos os serviços socioassistenciais". ${ }^{31}$

A Resolução 0001/2014 do CMAS de Abaeté instituiu critérios para concessão de benefício eventual na modalidade de auxílio-alimento:

\footnotetext{
Art. 1ㅇ - Instituir os critérios e prazos para concessão do benefício eventual na modalidade de auxílio-alimentação no âmbito do município de Abaeté/ MG. Art. 2o - O auxílio-alimentação será destinado às famílias em situação de vulnerabilidade e risco social; em caso de morte, abandono ou desemprego persistente do provedor do grupo familiar que ocasione incapacidade financeira no sustento de dependentes; e ainda em situação de emergência e/ou calamidade pública.
}

\footnotetext{
${ }^{28}$ Ata de reunião do CMAS de Abaeté realizada em 28 de agosto de 2007.

${ }^{29}$ Ata de reunião do CMAS de Abaeté realizada em 2 de agosto de 2010.

${ }^{30}$ Ata de reunião do CMAS de Abaeté realizada em 5 de fevereiro de 2014.

${ }^{31}$ Ata de reunião do CMAS de Abaeté realizada em 19 de fevereiro de 2014.
} 
Art. 3ㅇ - Para acesso ao benefício eventual, modalidade auxílio-alimentação, o usuário deverá procurar diretamente uma unidade pública prestadora de serviços de assistência social e efetuar a solicitação.

Art. 40 - A concessão do auxílio-alimentação deverá ocorrer exclusivamente através de profissional devidamente habilitado para análise da situação sociofamiliar e emissão de parecer.

Art. 5o - O prazo para a concessão do auxílio-alimentação não poderá ser superior a 05(cinco) dias contados a partir da data da solicitação efetuada pelo usuário (ABAETÉ, 2014).

Conforme dados da pesquisa, é extremamente complexo organizar e deliberar sobre as políticas de assistência social, bem como coordenar as ações de assistência. Para que haja efetividade, é necessário contar com uma equipe de conselheiros perseverantes, qualificados e que tenham autonomia para deliberar com vistas a colocar em prática a Política Municipal de Assistência por meio de programas e projetos adequados à realidade do município.

\section{Considerações finais}

O presente estudo buscou evidenciar a relevância dos Conselhos como instrumentos de participação popular no processo de elaboração das políticas sociais e ações de combate à pobreza. A importância dos Conselhos gestores é evidente por ser fruto de lutas da população pela provisão de serviços por parte do Estado. Ao mesmo tempo, os Conselhos representam a conquista de um espaço público institucionalizado em que representações do governo e da sociedade podem deliberar sobre políticas sociais.

Embora representem um marco na conquista e efetivação de direitos sociais, pesquisas mostram que esses espaços de participação política têm sido transformados em instâncias de referendo das ações dos gestores municipais, sendo comuns a definição e o controle das pautas pelas secretarias de governo. Além disso, tal como demonstrado por Tatagiba (2002), existem problemas relativos à paridade da representação, fato que afeta a partilha do poder, sendo corrente, também, a prática da autorrepresentação sem que os representantes do governo e da sociedade estabeleçam conexão com as bases representadas.

O tema relativo ao funcionamento dos Conselhos setoriais foi alvo de estudos diversos na década de 1990 e no início do século XXI. Muitos desses estudos foram 
voltados para o formato institucional e para a capacidade de se estabelecerem como espaços democráticos de formulação de políticas sociais. Recentemente, as preocupações se voltam para a existência e permanência dessas esferas como espaços de deliberação capazes de efetivar políticas.

Desde o marco legal de 1988, a participação da sociedade foi apresentada como fundamental para o desenho das políticas, bem como para seu monitoramento pela sociedade. Passados 26 anos desse marco legal estabelecido, são muitas as dificuldades de se consolidar os Conselhos como espaços deliberativos e de controle social, situação que tende a se apresentar mais frágil em cidades de menor porte em função de comportamentos comuns de controle assumidos pelos governos municipais. Incluem-se como entraves, além disso, a baixa qualificação das representações, o pouco amadurecimento político da sociedade civil e o predomínio de práticas domésticas nos processos de gestão pública.

\section{Referências}

ABAETÉ. Prefeitura Municipal. Lei no 2.515/2009. Dispõe sobre a alteração do Conselho Municipal de Assistência Social, do Fundo Municipal de Assistência Social, estabelece benefícios eventuais e dá outras providências. Abaeté, 2009. Disponível em: <http://migre.me/r6ej4>. Acesso em: 3 mar. 2014.

ABAETÉ. Prefeitura Municipal. Conselho Municipal de Assistência Social. - CMAS. Resolução no 0001/2014. Institui os critérios e prazos para concessão do benefício eventual na modalidade de auxílio-alimentação no âmbito do município de Abaeté. Abaeté, 2014.

AVRITZER, Leonardo. A qualidade da democracia e a questão da efetividade da participação: mapeando o debate. In: PIRES, Roberto Rocha C. (Org.). Efetividade das instituições participativas no Brasil: estratégias de avaliação. Brasília: IPEA, 2011.

BARROS, Ricardo Paes de; CARVALHO, Mirela de. Desafios para a política social brasileira. Texto para discussão no 985. Rio de Janeiro: IPEA, 2003.

BRASIL. Ministério do Desenvolvimento Social e Combate à Fome. Secretaria Nacional de Assistência Social. Política Nacional de Assistência Social (PNAS/2004) e Norma Operacional Básica (NOB/SUAS). Brasília, 2005.

BRASIL. Lei no 8.742, de 7 de dezembro de 1993. Vide Lei no 13.014, de 2014. Dispõe sobre a organização da Assistência Social e dá outras providências. 
COMERLATTO, Dunia; COLLISELLI, Liane; KLEBA, Maria Elizabeth; MATIELLO, Alexandre; RENK, Elisônia Carin. Gestão de políticas públicas e intersetorialidade: diálogo e construções essenciais para os conselhos municipais. Revista Katálysis, Florianópolis, v. 10, n. 2, p. 265-271, jul./dez., 2007.

CONSEAS-SP - Conselho Estadual de Assistência Social. Perguntas frequentes. São Paulo, 2014. Disponível em: <http://migre.me/r6eAc>. Acesso em: 22 fev. 2014.

CORREIA, M. V. C. Que é controle social na política de Assistência Social. Serviço Social e Sociedade, São Paulo, Ano 23, n. 72, p. 43-60, set. 2002.

IBGE - Instituto Brasileiro de Geografia e Estatística. Censo demográfico: informações completas - Minas Gerais - Abaeté. 2014. Disponível em: <http://migre.me/r6eFh>. Acesso em: 20 abr. 2014.

NETTO, José Paulo. Histórico da política de assistência social. Texto produzido para a Capacitação Regional de Conselheiros Estaduais e Municipais de Assistência Social. Ago., 2000. Disponível em: <http://www.mpes.gov.br/anexos/centros_apoio/ arquivos/ 11_2094171243852009_1_1_historico_politico_assistencia_social.pdf>. Acesso em: 22 fev. 2014.

PEDRINI, Dalila Maria; PINHEIRO, Márcia Maria Biondi. O controle social na Assistência Social. In: CONFERÊNCIA NACIONAL DE ASSISTÊNCIA SOCIAL, 5, 2005, Brasília. Cadernos de Estudos Desenvolvimento Social em Debate. Brasília, 2005.p. 34-43.

REIS, Carlos Nelson dos; PESTANO, Cíntia Ribes. A especificidade da Assistência Social: algumas notas reflexivas. Revista Virtual Textos \& Contextos, n. 5, p. 1-26, nov. 2006.

SANTOS, Mauro R. M. Conselhos municipais e a participação cívica na gestão das políticas públicas: o caso da metrópole fluminense. Cadernos Metrópole, São Paulo, n. 7, p. $97-$ 112, 1o sem. 2002. Disponível em: <http://migre.me/r6eKs>. Acesso em: 10 mar. 2002.

SILVA, Ilse Gomes. Democracia e participação na "reforma" do estado. São Paulo: Cortez, 2003.

TATAGIBA, Luciana. Os Conselhos Gestores e a Democratização das políticas públicas no Brasil. In: DAGNINO, Evelina (Org.). Sociedade civil e espaços públicos no Brasil. São Paulo: Paz e Terra, 2002. p. 47-103.

Recebido em: 09/08/2015

Aprovado em: 04/07/2016 